\title{
Modelos de proteção comercial: uma resenha
}

\author{
Models of commercial protection: a review
}

\author{
RENATO COLISTETE* \\ JARBAS DANTAS MENEZES**
}

\begin{abstract}
RESUMO: O protecionismo tem sido uma fonte permanente de disputas internacionais desde pelo menos o século XIX. Nas últimas décadas, uma série de barreiras não-tarifárias criou um novo fenômeno global, o chamado Novo Protecionismo, que mais uma vez mostra a eficácia das forças que levam à adoção de barreiras comerciais por parte das nações. Este artigo tem como objetivo revisar modelos analíticos representativos que lidam com as causas do protecionismo. Primeiro, o artigo discute modelos históricos de economia política e seu foco em grupos sociais, instituições e análises históricas. Em segundo lugar, o artigo aborda modelos de economia política positiva que trazem organizações, interesses e atores sociais ao quadro da escolha racional.

PALAVRAS-CHAVE: Proteção comercial; modelos de economia política; escolha racional; economia política histórica.
\end{abstract}

ABSTRACT: Protectionism has been an enduring source of international disputes since at least the nineteenth century. In the last decades, an array of nontariff barriers has created a new global phenomenon, the so-called New Protectionism, which once more shows the strength of the forces leading to the adoption of trade barriers by nations. This article aims to review representative analytical models which deal with the causes of protectionism. First, the article discusses historical political economy models and their focus on social groups, institutions and historical analysis. Second, the article addresses positive political economy models which bring organizations, interests and social actors into the framework of rational choice.

KEYWORDS: Trade protection; political economy models; rational choice; historical political economy.

JEL Classification: F13.

* Departamento de Economia e programa de pós-graduação em Economia, Universidade Estadual Paulista de Araraquara - UNESP-Araraquara, Araraquara/SP, Brasil. E-mail: renatoc@fclar.unesp.br

** Mestre em Economia da Universidade Estadual Paulista de Araraquara - Unesp/Araraquara, Araraquara/SP, Brasil. E-mail jdmenezes@ig.com.br. Submetido: março 2003; aceito: maio 2003. 


\section{INTRODUÇÃO}

Nas décadas seguintes após a II Guerra Mundial, a perda relativa de competitividade da economia americana diante de rivais europeus, asiáticos e de partes emergentes do globo traduziu-se em progressivos resultados comerciais desfavoráveis. O efeito direto foi o acúmulo de déficits comerciais e o aumento substancial das pressões protecionistas por parte de setores domésticos afetados pela nova situação competitiva internacional. Como resultado, a economia americana passou a sofrer pressões suficientemente fortes para que o compromisso de sua política externa com o livre-comércio, estabelecido nos anos do imediato pós-II Guerra Mundial, entrasse em franco conflito com os interesses ameaçados pela competição internacional. A emergência do novo protecionismo - como passou a ser conhecida essa nova onda protecionista, agora baseada em barreiras não-tarifárias e em grande medida oriunda de países desenvolvidos - mostrou eloqüentemente que políticas de proteção comercial não eram apenas anomalias ou traços passageiros em contextos históricos turbulentos, mas correspondiam a respostas de grupos sociais e de interesse, de Estados nacionais e setores econômicos, de políticas econômicas e estratégias nacionais diante de mudanças nas condições econômicas e relações de poder internacionais. Enfim, o protecionismo era um fenômeno muito mais complexo e persistente do que preconizavam os construtores da nova ordem mundial do pós-II Guerra.

O reconhecimento da complexidade e importância da proteção comercial não constitui uma novidade para um grupo expressivo de autores que têm procurado explorar as relações entre economia e política, de um lado, e suas dimensões domésticas e internacionais, de outro. Desde os anos 40 do século XX pelo menos, estudiosos têm buscado entender as relações entre forças sociais, instituições e a economia doméstica e internacional no condicionamento das medidas protecionistas adotadas pelos governos. O nome de Alexander Gerschenkron, conhecido por seus estudos pioneiros sobre as condições do desenvolvimento econômico tardio, é o principal representante desse esforço original no campo do que se poderia chamar de economia política histórica. Por outro lado, outro tipo de abordagem da proteção comercial, baseada em modelos teóricos formais, tem procurado endogeneizar variáveis sociais e políticas para explicar as causas do protecionismo. Essa última perspectiva constitui o que será chamado aqui de modelos da economia política positiva.

O objetivo desse artigo é realizar um levantamento desses esforços teóricos de explicação do protecionismo enquanto um fenômeno complexo e significativo, que constitui um aspecto importante da história econômica de setores econômicos e nações. Para tanto, a análise dos textos é distribuída entre as duas abordagens mencionadas acima - modelos da economia política histórica (seção 2) e da economia política positiva (seção 3). Evitando uma apresentação exaustiva da literatura, a discussão a seguir é feita a partir de autores e trabalhos selecionados que permitem 
ilustrar as principais questões tematizadas, as diferentes perspectivas e as distintas explicações que têm sido propostas quanto aos que seriam os determinantes fundamentais do protecionismo. Nos comentários finais (seção 4), são discutidos os limites e problemas relacionados com cada uma das abordagens.

\section{PROTECIONISMO E A ECONOMIA POLÍTICA HISTÓRICA}

A análise teórica e histórica do protecionismo tem sido tradicionalmente uma das principais áreas de investigação por parte de autores preocupados com a economia política das nações e suas dimensões domésticas e internacionais vistas de uma perspectiva histórica. Essas abordagens deram origem ao que é aqui chamado de modelos da economia política histórica. ${ }^{1}$ Esses modelos baseiam-se em descrições estilizadas de realidades históricas e sociais, com pouca ou nenhuma formalização matemática, embora partam de marcos teóricos gerais (por exemplo, marxistas e weberianos, ou combinações entre eles) que adotam conceitos-chave como classes sociais, grupos de interesse, Estado e hegemonia. De forma resumida, é possível identificar quatro variantes de interpretação dos determinantes básicos dos regimes de proteção comercial nos modelos da economia política histórica. Há autores que definem os grupos de pressão como os principais determinantes da política comercial. Outros enfatizam a posição do país no sistema econômico e político internacional, enquanto outras interpretações destacam ainda as idéias e o Estado como as principais forças que condicionam a adoção de sistemas de proteção específicos (Gourevitch, 1977, p. 98-9). A discussão a seguir apresenta uma síntese de alguns modelos aplicados a distintos contextos históricos e países, dando maior ênfase à primeira variante, que enfatiza o papel dos grupos de interesse.

Um estudo pioneiro sobre o protecionismo dentro da tradição da economia política histórica foi o de Alexander Gerschenkron (1943), que introduziu explicitamente a ação de grupos de interesse na análise da política de proteção. O foco da análise de Gerschenkron recaiu sobre a elite proprietária rural junker, que se tornou a principal base de apoio aos príncipes prussianos e, depois da Unificação Alemã conduzida por Bismarck em 1870-71, ao novo Estado nacional alemão até meados do século XX. Depois de um breve experimento com o livre-comércio nos anos 1860 e 1870, os junkers do leste da Prússia tiveram sua posição nos mercados internacionais seriamente ameaçada com o início da grande crise em 1873 e com a emergência de competidores (Estados Unidos e Canadá) nos mercados internacionais de grãos.

Em vista desse quadro internacional crítico, os junkers passaram já em 1877 a reivindicar medidas compensatórias, na forma de tarifas sobre a importação de

\footnotetext{
${ }^{1}$ Para uma definição de economia política histórica, ver Maier (1987).
} 
grãos que mantivessem elevados os preços internos. Fragilizado internamente, ao final dos anos 70 do século XIX, Bismarck abandonou a aliança parlamentar com os liberais que havia sido essencial para o sucesso da Unificação e formou uma nova coalizão, desta vez apoiada nos grandes proprietários junkers do leste e nos cristãosdemocratas. Em 1879 e em anos subseqüentes (1885 e 1887), o governo de Bismarck rompeu o compromisso anterior com o livre-comércio e introduziu tarifas crescentes sobre grãos a fim de proteger os grandes agricultores da concorrência internacional. Além dos produtos agrícolas, as tarifas também foram aplicadas aos produtos manufaturados da grande indústria siderúrgica alemã, que despontara como principal setor econômico em expansão na segunda metade do século XIX, mas que passou também a sofrer diretamente com o ciclo econômico, a queda dos preços e a acirrada concorrência internacional. Reagindo rapidamente a tais condições adversas, as grandes empresas siderúrgicas engajaram-se em uma ativa campanha protecionista em 1876, que passou a contar com o apoio dos junkers no ano seguinte. Esta convergência de interesses veio a formar o que Gerschenkron chamou de aliança entre "centeio e ferro" (rye and iron), ou seja, entre a grande agricultura exportadora e a indústria pesada, que estaria na origem da adoção das tarifas protecionistas a partir de 1879 na Alemanha.

O principal objetivo de Gerschenkron foi entender a razão pela qual os junkers, a despeito de sua importância econômica declinante durante o século XIX e início do século XX, retiveram sua influência social e política e foram capazes de condicionar decisivamente uma matéria estratégica como a política comercial. O problema tornava-se ainda mais complexo porque a imposição das tarifas sobre grãos representou um aumento substancial dos custos para agricultores do sul e oeste da Alemanha, indústrias leves e trabalhadores. A resposta de Gerschenkron ao quebra-cabeça da política tarifária de Bismarck consistiu, primeiro, em enfatizar a existência de interesses conflitantes entre setores econômicos e no interior de grupos sociais, de acordo com os tipos de bens produzidos, sua inserção no comércio internacional e sua capacidade competitiva. Segundo, Gerschenkron destacou a influência política e ideológica de um grupo social (junkers) e sua capacidade de promover uma coalizão bem-sucedida com outros grupos de interesse (sobretudo a indústria pesada) em favor da criação e elevação das tarifas - alienando, ao mesmo tempo, a indústria leve (bens de consumo) e a pequena e média agriculturas destinadas ao mercado interno (Gerschenkron, 1943, parte I).

O estudo de Gerschenkron foi marcante enquanto um esforço pioneiro de análise da economia política do protecionismo a partir da ação e influência de grupos de interesse. Outros autores seguiram o mesmo caminho, aplicando o modelo adotado por Gerschenkron em outros contextos históricos e temas. Um exemplo influente é o trabalho de Charles Kindleberger (1951). Kindleberger propôsse a analisar as diferentes respostas de economias nacionais diante das mudanças no comércio internacional durante o período da grande depressão de 1873-1896. O autor examinou os resultados diferenciados da crise no Reino Unido, Alemanha e 
Dinamarca, dando ênfase (como Gerschenkron) ao papel de grupos e subgrupos sociais no condicionamento das políticas comerciais. Enquanto a Alemanha reagiu à crise através da criação de tarifas, tanto na Dinamarca como no Reino Unido ocorreu um amplo processo de ajuste da produção agrícola, que excluiu a adoção de barreiras comerciais. No caso do Reino Unido, o ajuste implicou a redução da produção dos bens agrícolas que competiam com importações, a reorientação dos investimentos para outros cultivos e, ao final, um declínio significativo da população agrária. Na Dinamarca, o ajuste deu-se através do abandono da exportação de trigo e a reorientação da agricultura para a produção de laticínios de alto valor agregado sob o sistema de cooperativas, mantendo uma alta proporção da população empregada na agricultura. De acordo com Kindleberger, as diferentes alternativas seguidas pelos países só poderiam ser entendidas a partir do estudo detalhado das estratégias de grupos e subgrupos sociais nos países em questão (Kindleberger, 1951, p. 306-11). ${ }^{2}$

Mais recentemente, Barry Eichengreen (1989) adotou explicitamente um modelo de economia política da proteção inspirado em Gerschenkron a fim de examinar as origens do Tariff Act (conhecida como Smoot-Hawley Tariff) de 1930, nos Estados Unidos. A Smoot-Hawley Tariff notabilizou-se pela sua abrangência (envolvendo mais de 20.000 produtos) e ativa militância de grupos de pressão no Congresso americano. Tal como Gerschenkron, Eichengreen deu ênfase às distinções entre grande e pequena indústria e às diferenças regionais entre produtores na definição de suas posições no processo de barganha que conduziu à adoção de barreiras protecionistas. Contudo, Eichengreen tratou de maneira ainda mais explícita do que Gerschenkron o fato de os bens de exportação (e os que sofrem a concorrência de importados) serem freqüentemente heterogêneos e os mercados regionais fragmentados. No caso dos Estados Unidos, por exemplo, havia diferenças substanciais entre produtores de grãos do norte e leste do país frente aos de outras regiões, assim como entre indústrias leves, que atuavam em mercados segmentados, e a indústria pesada, que produzia bens padronizados para exportação. Tanto a indústria leve como a agricultura de grãos do norte e leste americano defenderam a adoção de tarifas específicas, ameaçados como estavam pela concorrência externa. Segundo Eichengreen, o resultado final foi que, apesar de não possuírem qualquer identidade entre si, as pressões particularistas daqueles grupos de interesse foram eficazes o suficiente para produzir um aumento generalizado das tarifas e da proteção comercial nos Estados Unidos a partir dos anos 30 do século XX (Eichengreen, 1989, 43-6).

Ainda que com preocupações semelhantes às dos trabalhos comentados acima, outros autores têm seguido abordagens teóricas alternativas às mencionadas sobre o papel dos grupos de interesse. Um exemplo é Ronald Rogowski (1989), em seu

\footnotetext{
${ }^{2}$ A análise de Kindleberger, porém, foi essencialmente exploratória, não investigando detalhadamente as condições dos grupos sociais domésticos, o que teria levado a respostas distintas à crise.
} 
livro Commerce and Coalitions. Rogowski tomou como ponto de partida o teorema Stolper-Samuelson, segundo o qual o comércio beneficia os proprietários dos fatores de produção abundantes e diminui as rendas dos proprietários de fatores escassos através das mudanças dos preços relativos de bens e fatores. Inversamente, o teorema sugere que a proteção comercial penaliza a produção especializada do fator abundante e permite que os produtores que utilizam fatores escassos apropriem-se de rendas derivadas de sua escassez. ${ }^{3} \mathrm{O}$ objetivo de Rogowski foi explorar as conseqüências desse modelo em termos das atitudes dos grupos sociais que são beneficiados ou prejudicados com o comércio internacional. Assim, por exemplo, em uma economia rica em trabalho e pobre em capital, a proteção iria beneficiar este último em detrimento dos proprietários do fator trabalho. Com isso, seria possível predizer o comportamento de grupos sociais quanto ao protecionismo dependendo da abundância ou escassez relativa dos fatores em uma sociedade específica. Rogowski reconhece as limitações do modelo (por exemplo, a hipótese de interesses homogêneos no interior de grupos sociais), mas sustenta que esse é um ponto de partida útil para o estudo dos alinhamentos políticos de grupos sociais em um contexto de mudanças no comércio internacional (Rogowski, 1989, cap. 1).

Em geral, as abordagens comentadas acima possuem em comum o fato de verem os grupos de interesse como o principal determinante dos regimes comerciais em distintos contextos históricos. Para autores como Gerschenkron, os resultados da ação de grupos de interesse dependem em grande medida de seu poder de pressão e influência política, das organizações estatais, dos tipos de bens produzidos e das condições variáveis da economia internacional - como foi visto anteriormente. Outros autores, porém, tendem a rejeitar a primazia analítica dos grupos de interesse e a chamar a atenção para outros fatores na determinação das políticas comerciais - Estado, sistema internacional, ideologias. Um exemplo influente é o de Stephen Krasner (1976), que desenvolveu uma interpretação das relações entre economia doméstica e comércio internacional que enfatiza o sistema internacional de poder constituído pelos Estados Nacionais. Segundo Krasner, os Estados perseguem quatro objetivos gerais que são diretamente afetados pela estrutura do comércio internacional: poder político, renda nacional, crescimento econômico e estabilidade social. A forma como cada um destes elementos pode ser afetado pelo comércio internacional (abertura ou proteção) dependeria, por sua vez, do tamanho relativo e nível de desenvolvimento da economia em questão. Assim, por exemplo, os impactos da abertura comercial sobre a estabilidade social tenderiam a ser maiores em economias pequenas (por serem mais dependentes do comércio externo) do que em economias de grande porte (com pequeno peso do comércio internacional na renda agregada). A partir de resultados gerais como esse seria possível prever o

\footnotetext{
${ }^{3}$ Ver por exemplo Winters (1991) p. 39-40.
} 
comportamento de Estados específicos diante das mudanças do comércio internacional (Krasner, 1976, p. 21-3).

Outros autores têm procurado combinar uma visão centrada no Estado com o papel das idéias na explicação das políticas comerciais. Judith Goldstein (1988), por exemplo, ao examinar a política comercial americana no século XX, argumentou que as organizações do Estado reúnem interesses distintos e mudam apenas lentamente, mantendo princípios e políticas muitas vezes contraditórios com novos ambientes econômicos. Por outro lado, segundo Goldstein, tão importante quanto as instituições para a explicação da política comercial seria o sistema de idéias que norteia as ações dos indivíduos influentes na formulação das leis e políticas. $\mathrm{Na}$ opinião da autora, o liberalismo foi a principal força ideológica que orientou a política econômica externa nos Estados Unidos a partir da Depressão dos anos 1930, em grande parte como uma reação à política exclusivista de grupos de interesses, guerra e políticas comerciais agressivas que marcaram aquela época. Não obstante a hegemonia das idéias liberais, a política econômica externa norte-americana foi desde então cercada de contradições, sobretudo pela permanência de instrumentos protecionistas que continuaram sendo utilizados por interesses particularistas. Organizações como a International Trade Commission e instrumentos como a legislação antidumping (que protege produtores afetados por concorrência via preços abaixo dos custos) são todos mecanismos, segundo Goldstein, que sobreviveram à hegemonia da visão liberal nas relações econômicas externas, em grande medida devido à inércia das instituições criadas no contexto altamente protecionista dos anos 20 e início dos anos 30 do século XX (Goldstein, 1988, p. 391-8).

Na próxima seção será apresentado um conjunto de trabalhos que se diferencia significativamente em termos de perspectiva metodológica daqueles vistos até agora. Geralmente formalizados e apoiados nas hipóteses da teoria da ação coletiva e da escolha racional, os modelos da economia política positiva vistos a seguir procuram definir resultados que possam ser testados empiricamente e, com isso, identificar os atores envolvidos e as causas mais importantes da proteção comercial.

\section{MODELOS DA ECONOMIA POLÍTICA POSITIVA}

A adoção de políticas comerciais e protecionistas tem sido crescentemente estudada em modelos econômicos formais que procuram introduzir interesses de grupos sociais e condicionantes políticos na análise. Os estudos realizados segundo essa abordagem consideram que as políticas comerciais sofrem a influência direta de grupos de interesse, em vez de serem determinadas independentemente pelo governo. Quando são capazes de superar os problemas da ação coletiva, os grupos de interesse agem de forma organizada (lobby) a fim de maximizar as utilidades de seus membros. O grau de sucesso desse tipo de ação coletiva tende, por sua vez, a estar vinculado a determinadas características (tamanho, dispersão geográfica, tem- 
po de organização) exibidas pelos grupos de pressão (Olson, 1965). Tais modelos são aqui classificados como representantes da economia política positiva (Ordeshook, 1990).

Com relação à ação governamental, os modelos da economia política positiva assumem em geral que os governos, através de políticos e partidos, tendem a ser suscetíveis às pressões de grupos de interesse em busca de benefícios políticos quando a indústria emprega um grande número de trabalhadores (o que implica um grande número de eleitores), gera elevados níveis de renda (que tende a significar grandes contribuições para campanhas políticas) ou paga baixos salários (a proteção desse setor e dos trabalhadores tende a contar com apoio da opinião pública). Por outro lado, os governos podem rejeitar pressões protecionistas se um grande número de consumidores for prejudicado. Ainda assim, os governos contam, primeiro, com a falta de organização dos consumidores, que por serem numerosos e dispersos não possuem a mesma capacidade de organização que as empresas de um determinado setor; e, segundo, com a existência de informações imperfeitas sobre os custos do protecionismo, em termos do preço relativo de um produto final. Assim, os governos tendem a ser mais sensíveis às pressões de grupos econômicos do que de consumidores.

Os modelos da economia política positiva também levam em conta a possibilidade de independência frente a grupos de interesses na formulação das políticas comerciais, quando essas últimas são sujeitas aos condicionantes de interesses externos e dos interesses da economia em geral. Assim, por exemplo, os governos podem procurar não ferir acordos comerciais internacionais a fim de não serem sujeitos a retaliações ou a disputas comerciais danosas. Do ponto de vista da economia como um todo, a proteção de um setor de produtos intermediários, por exemplo, poderia fazer com que outros setores perdessem competitividade. Em resumo, na maior parte dos modelos de proteção da economia política positiva, as políticas comerciais e protecionistas são de natureza endógena devido à influência dos grupos de interesse ou de natureza exógena em virtude da perspectiva mais ampla que pode ser adotada pelos governos. $\mathrm{Na}$ discussão a seguir, serão apresentados primeiramente alguns modelos que ilustram a ênfase em interesses internos dos governos e, em seguida, outros que assumem a determinação exógena da política comercial. O trabalho de Hillman (1982) é um exemplo importante da análise do comportamento de governos frente a pressões protecionistas por parte de indústrias em declínio. Segundo esse autor, o governo procura maximizar seu suporte político quando indústrias enfrentam dificuldades causadas por quedas sustentadas nos preços internacionais que ameaçam a existência da própria indústria. Sob tais circunstâncias, a resposta do governo é a de determinar qual será o nível dos preços domésticos (ou o grau de proteção) na nova situação internacional. Assim, o modelo proposto procura estabelecer o preço que vai refletir a maximização pelas autoridades do suporte político da indústria em questão. De acordo com o modelo, maiores lucros conduzem a maior suporte político, enquanto que os lucros 
aumentam devido à proteção (aumento dos preços domésticos), o que pode levar a maior suporte político. Portanto, o governo pode regular seu suporte político através da regulação dos preços domésticos, de tal modo que o nível dos lucros satisfaça a indústria.

Em princípio seria de esperar que uma queda nos preços internacionais fosse totalmente compensada pelas autoridades com o aumento da tarifa de importação, dado o modelo apresentado acima. Contudo, somente ocorreria tal resultado caso não houvesse outros fatores que determinassem a maximização do suporte político. Há modelos, porém, que levam em conta os interesses dos consumidores nas políticas adotadas pelo governo. Hillman (1982), por exemplo, introduz na função do suporte político a influência dos agentes que perdem com a proteção, de modo que os interesses dos perdedores (consumidores) são considerados na determinação do preço doméstico e, conseqüentemente, da maximização do suporte político.

O resultado da inclusão dessa última variável (agentes que perdem com a proteção), em uma situação de queda dos preços internacionais, é que as autoridades tendem a impor uma tarifa que não compense totalmente tal declínio, de forma que os preços domésticos aumentarão menos do que o fariam caso os interesses dos consumidores não fossem contemplados. Entretanto, se a queda dos preços internacionais for persistente, será cada vez mais difícil continuar a compensar a indústria, pois o declínio dela será cada vez mais nítido e os interesses dos consumidores tenderão a tornar-se cada vez mais importantes. Diante disso, as autoridades provavelmente diminuirão a proteção da indústria. Uma implicação do modelo é que a imposição de tarifas não seria capaz de conter a redução de importância da indústria, conseguindo tal política somente diminuir a velocidade de seu declínio.

Com o objetivo de analisar a influência das contribuições financeiras sobre os governos, Grossman \& Helpman (1994) apresentaram uma outra abordagem para a determinação de políticas protecionistas. Os autores destacam a competição política entre candidatos, em que cada um apresenta uma política comercial distinta a ser adotada caso eleito. Desse modo, grupos de interesse avaliariam as propostas apresentadas e apoiariam aquela que lhes garantisse a maximização de seus benefícios. O apoio é medido através de contribuições às campanhas políticas dos candidatos, com as quais os grupos esperam influenciar a política a ser adotada. O objetivo do modelo de Grossman e Helpman é identificar a razão do sucesso de determinados grupos em obter benefícios protecionistas, o motivo das preferências desses grupos por determinadas políticas e os interesses dos políticos que fazem escolhas de políticas conscientes de que estas podem afetar suas chances de eleição ou reeleição. $\mathrm{O}$ modelo assume que os governos são capazes de modificar a política protecionista em razão de algum impacto externo sem que essa mudança gere insatisfação entre outros grupos ou indivíduos, ou seja, pressupõe que o governo é capaz de definir a política comercial a ser adotada a fim de maximizar as contribuições totais e o bem-estar social. O equilíbrio dos interesses é encontrado levan- 
do em conta o poder relativo dos grupos envolvidos e os parâmetros da política comercial nacional.

Ainda no modelo de Grossman \& Helpman (1994), cada grupo estabelece sua preferência por determinada política e respectiva contribuição, enquanto o governo coleta todas as contribuições e pondera suas respectivas escolhas políticas, a partir das quais obtém-se um equilíbrio de interesses em função das contribuições oferecidas. Nesse caso, a obtenção do equilíbrio corresponde a saber qual a política de preços domésticos que será adotada ou, em outras palavras, qual o nível de proteção que será imposto. A condição apresentada diz que, dado o valor da contribuição, o governo estabelece um nível de proteção (tarifa) condizente com esse valor no ponto em que maximize os interesses dos grupos. Para obter maior proteção, o lobista deve oferecer uma maior contribuição, de forma que uma variação do valor da contribuição levará a uma variação na política adotada. Contudo, a obtenção de benefícios protecionistas através de contribuições pode alcançar um limite em que o aumento da contribuição não levará a nenhuma vantagem. Nesse ponto, dados os outros fatores, o valor da contribuição torna-se constante e o equilíbrio é alcançado entre os interesses existentes. Esse modelo é bastante restritivo por tratar somente de um aspecto das pressões protecionistas. Porém, o aspecto abordado - benefícios protecionistas através de contribuições — é importante por não receber a mesma ênfase em outros modelos.

Os dois modelos apresentados até agora abordaram a formulação de políticas protecionistas através de barreiras tarifárias - que constituem apenas uma das formas de proteção comercial. Nas últimas décadas, a utilização de Barreiras NãoTarifárias (BNTs) tem se tornado cada vez mais importante, sobretudo nas economias avançadas. Um modelo que incorpora as BNTs foi elaboradopor Rosendorf (1996), que trata da preferência do governo em negociar Restrições Voluntárias às Exportações (VERs) ou impor sobretaxas anti-dumping ao invés de adotar tarifas de importação. O modelo de Rosendorf concentra-se na negociação de VERs como uma alternativa à imposição de sobretaxas anti-dumping, pois, segundo o autor, as ações anti-dumping antecedem as VERs. Ao iniciar investigações anti-dumping, as autoridades responsáveis já sinalizam a intenção de impor sobretaxas. Essa situação induz os exportadores estrangeiros a aceitar ou propor algum tipo de negociação que diminua suas perdas, negociação esta representada pela diminuição voluntária das exportações. Quando a indústria doméstica é influente politicamente e inicia um pedido de investigação anti-dumping, o governo impõe uma sobretaxa antidumping preliminar alta o suficiente para incentivar os produtores estrangeiros a propor uma combinação entre um novo valor da sobretaxa e um novo nível de exportações. No caso da sobretaxa ser baixa, haveria a indicação de que os interesses dos consumidores são dominantes, pois a imposição de uma sobretaxa baixa teria poucos efeitos sobre os preços domésticos e os interesses dos consumidores não seriam afetados significativamente. O governo poderia rejeitar a proposta dos produtores estrangeiros (imposição definitiva da sobretaxa preliminar) ou aceitála, o 
que nesse último caso permitiria concluir que a proposta é interessante do ponto de vista da indústria doméstica e, portanto, dos interesses políticos do governo. O governo tende a obter maiores vantagens políticas com este procedimento, pois consegue o retorno eleitoral esperado ao proteger os interesses da indústria doméstica sem gerar oposição dos consumidores.

A contribuição do modelo de Rosendorf encontra-se na ênfase dada às vantagens políticas de um governo adotar BNTs. Ainda assim, o caráter político conferido à determinação da margem de dumping tem sido bastante questionado. Outros estudos enfatizam, ao contrário, o caráter técnico da margem de dumping, de forma que a pressão política se daria em outras áreas do processo protecionista. $\mathrm{O}$ estudo elaborado por Finger; Hall \& Nelson (1982) apresenta uma versão dessa última abordagem. Os autores distingüem o caráter técnico e político das políticas protecionistas, mais especificamente da determinação de dumping e de dano à indústria. O caráter técnico (low track) é baseado em regras e determinações de acordo com os critérios estabelecidos pela legislação vigente, enquanto o caráter político ( high track) é menos sujeito às regulações e requer considerável atenção pelos governos. Sendo assim, a determinação da margem de dumping tende a assumir um caráter técnico, enquanto a determinação de dano (pela sua natureza menos precisa) teria um caráter político. ${ }^{4}$ Desse modo, o alvo de pressão dos grupos de interesse tende a ser dirigido para o lado político da determinação da proteção. Para testar essas hipóteses, os autores realizaram um estudo empírico sobre as determinações de dumping e de dano nos Estados Unidos entre 1975 e 1979, onde consideraram os fatores técnicos - custos comparativos (razão capital-trabalho, média salarial e economias de escala) e precisão técnica (número de produtos cobertos pelo caso) - além de fatores políticos - influência doméstica (concentração e tamanho da indústria, emprego, tamanho do caso) e influência internacional (proporção das exportações para o país investigado e para países em desenvolvimento). Os resultados encontrados corroboraram em grande medida as hipóteses apresentadas. Quase todos os fatores políticos (exceto nível de emprego) não apresentaram correlação com os resultados das determinações de dumping (low track), principalmente com relação à influência externa. Por outro lado, em relação à determinação de dano (high track), os fatores políticos (principalmente o tamanho do caso) pareceram ser bem mais influentes do que os fatores técnicos, embora a influência externa também não tenha demonstrado ser significativa.

Os modelos apresentados acima trataram principalmente dos interesses internos dos governos sobre a determinação de políticas protecionistas. Contudo, é comum a preocupação por parte dos governos em não ferir acordos internacionais a fim de evitar retaliações dos parceiros comerciais. Desse ponto de vista, a política determinada internamente fica limitada pelas circunstâncias externas. Uma das so-

\footnotetext{
${ }^{4}$ Segundo regras internacionais de comércio é preciso ser comprovado o dano à indústria nacional para a imposição de sobretaxas anti-dumping.
} 
luções apontadas, dada uma política protecionista, é que exportadores estrangeiros prejudicados recebam parte da renda extra auferida em razão do aumento nos preços do mercado importador. A título de exemplo, Araújo Jr. (1995) tratou desta questão utilizando o jogo de superposição, definido de modo que um determinado jogador (governo) participa ao mesmo tempo de jogos contra oponentes distintos (produtores domésticos e estrangeiros) e que a estratégia aplicada em um jogo limita as estratégias disponíveis no outro.

Distribuindo os jogadores entre o país de origem e o resto do mundo e as estratégias entre livre-comércio e protecionismo, temos a matriz de recompensas:

Figura 1: Matriz de Recompensas

\begin{tabular}{c|c|c|c}
\hline & \multicolumn{3}{|c}{ Resto do mundo } \\
\hline & & Livre-comércio & Proteção \\
\hline País de origem & Livre-comércio & 0,0 & $0, \mathrm{Br}$ \\
\hline & Proteção & $\mathrm{Bh}, 0$ & $\mathrm{Bh}^{*}, \mathrm{Br}^{*}$ \\
\hline
\end{tabular}

Se ambos os jogadores escolhem o livre-comércio, temos os consumidores com livre acesso aos produtos, pagando por eles o preço internacional. Se um jogador escolhe proteção, sua recompensa é B (Bh para o país de origem e Br para o resto do mundo), o que equivale aos benefícios esperados de sua política interna, em que todos custos são pagos pelo parceiro comercial prejudicado. Se ambos preferem proteção, a recompensa será $\mathrm{B}^{*}$, que por definição é menor que $\mathrm{B}$.

Supondo que o jogo internacional começa somente depois que dentro do jogo nacional as estratégias protecionistas são aprovadas nos países, o equilíbrio inicial é $\mathrm{Bh}^{*}$ e $\mathrm{Br}$ *. Contudo, essas recompensas dependem da duração das políticas nacionais, já que períodos de protecionismo maiores tendem a ser mais custosos, ou seja, a diferença entre B e B* tende a ampliar-se, o que tende a desestimular a continuidade da proteção. Deste modo, os governos reavaliarão suas posições no futuro. A partir disso, em cada rodada do jogo nacional, os jogadores tomarão nota das novas restrições impostas pela situação internacional e revisarão suas estratégias. Do mesmo modo, cada rodada do jogo internacional terá um equilíbrio transitório que refletirá os valores momentâneos de B e B*, e assim sucessivamente. O resultado será que o país que adotar o protecionismo procurará negociar com os parceiros comerciais uma redistribuição das rendas da proteção, que permitirá que esses parceiros mantenham a política de livre-comércio. Os países tenderão a entrar em acordo tendo em vista que políticas protecionistas mútuas serão mais custosas para todos. Assim, a barganha internacional cumpre duas funções: primeiro, assegura a recompensa correta de cada jogador e, segundo, indica as quantidades corretas dos custos e benefícios gerados pelas políticas nacionais.

Em um ambiente favorável de livre-comércio, a proteção de uma determinada indústria pode fazer com que os parceiros comerciais exijam parte da renda da proteção, em vez de promover retaliações comerciais. Como indicado na Figura 2, 
o país pode propor uma VER, de modo que os preços sobem de $o c$ para oa e os exportadores perdem a renda equivalente à área $e d f g$, mas recebem nova renda equivalente à área $a b d c$ :

Figura 2: Rendas de Proteção para o Resto do Mundo

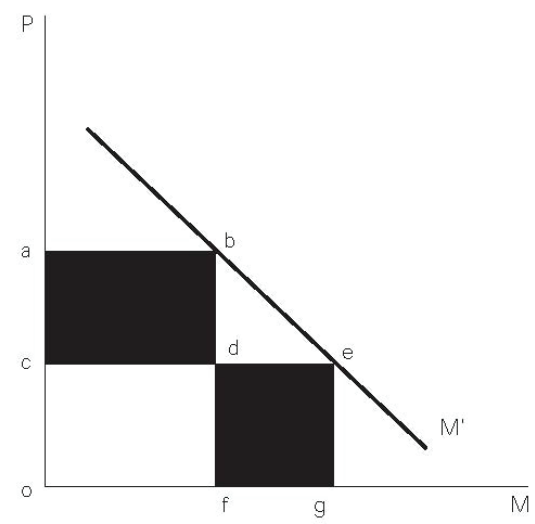

Desta forma, um país pode adotar a proteção como alternativa, enquanto que o resto do mundo pode continuar com a política de livre-comércio, já que as recompensas foram pagas de um modo alternativo em relação à matriz de recompensas.

Em seu trabalho, Araújo Jr. introduziu as ações dos exportadores prejudicados dada a política protecionista do país de origem. Já em outro estudo, Hillman \& Ursprung (1988) propuseram uma abordagem diferente, em que consideraram a influência de empresas estrangeiras na determinação das políticas protecionistas. Nesse último trabalho, os autores apontaram a preferência dos governos em negociar VERs, em vez de impor tarifas, como uma evidência da influência explícita dos interesses externos sobre as políticas protecionistas. A participação estrangeira na política doméstica poderia tomar a forma de contribuições em campanhas políticas ou outro tipo de transferência que influenciasse a política comercial proposta pelo candidato a cargo eletivo majoritário. Em função da competição política, os candidatos tenderiam a assumir uma política de equilíbrio entre os interesses dos produtores domésticos e estrangeiros (os interesses dos consumidores não assumem um papel ativo nesse modelo), em que a VER permitiria ganhos mútuos entre os produtores.

Ainda nesse modelo, quando a restrição voluntária beneficiasse ambos os produtores, os candidatos tenderiam a adotar a mesma proposta quanto a política protecionista, pois assim ambos poderiam maximizar as contribuições obtidas. $\mathrm{O}$ modelo também apresentou a possibilidade de um acordo que garantisse benefícios maiores aos produtores estrangeiros. Entretanto, verifica-se que, nos Estados Unidos por exemplo, muitas VERs resultaram de negociações alternativas à imposição de sobretaxas anti-dumping (como apontado anteriormente por Rosendorf). Des- 
ta forma, os produtores estrangeiros podem aceitar o acordo como forma de minimizar as perdas, podendo-se imaginar, assim, que o poder de uma indústria estrangeira sobre a determinação de políticas protecionistas não seja tão significativo.

Os estudos apresentados até o momento utilizam modelos que se concentram nos atores envolvidos na formulação de políticas protecionistas. Uma questão adicional é o motivo pelo qual algumas indústrias pressionam seus governos por proteção comercial. Vários estudos apontam para problemas macroeconômicos (recessão, câmbio valorizado) enquanto outros dão ênfase à perda de competitividade associada ao crescimento relativamente baixo da produtividade, mudança nas vantagens comparativas ou mesmo obsolescência tecnológica como causas das pressões protecionistas. ${ }^{5}$ Lenway; Morck \& Young (1996), por exemplo, procuraram caracterizar o protecionismo na indústria norte-americana do aço através da análise das empresas lobistas e não-lobistas. Os autores examinaram 130 empresas do aço, dentre as quais 36 foram lobistas durante o período e 1977 a 1988. Os resultados verificados mostraram que as empresas lobistas tenderam a ser maiores, mais antigas, menos diversificadas, menos lucrativas e investiam menos em P\&D do que as empresas não-lobistas, além de pagarem maiores salários para os trabalhadores e diretores. Outro resultado foi o de que, quando a proteção é imposta, as empresas lobistas demitem mais, o que reduziria a validade do argumento da importância social da proteção em termos de preservação do emprego.

Ainda segundo Lenway, Morck e Young, por serem maiores, as empresas lobistas poderiam utilizar suas escalas de produção como fator de pressão, ao mesmo tempo em que, por serem menos diversificadas, teriam maiores dificuldades de sair da indústria. Igualmente, como são menos eficientes, as empresas lobistas seriam obrigadas a cortar empregos como forma de reduzir custos salariais reais. Em períodos de proteção, tais empresas tenderiam a ser menos inovadoras (pois reduziriam ainda mais os investimentos em P\&D) e reagiriam a aumentos da demanda com maiores aumentos de preços. A partir desses resultados, Lenway, Morck e Young apresentaram uma posição contrária aos argumentos das empresas em favor de proteção. Primeiro, as empresas sustentam que a proteção garantiria a manutenção dos empregos, o que na opinião daqueles autores seria falso, já que por terem menores níveis de produtividade o corte de emprego acabaria sendo a melhor solução para o ajuste do setor. Segundo, as empresas podem argumentar que um período de proteção corresponderia a um período de adaptação para a indústria, que poderia reestruturarse e futuramente voltar a ser competitiva. Contudo, o que se verifica geralmente, segundo os autores, seria a queda do investimento em P\&D em períodos de proteção, com efeitos nulos ou perda de eficiência.

\footnotetext{
${ }^{5}$ Para uma resenha, ver POTTERS \& SLOOF (1996).
} 


\section{CONCLUSÕES}

A breve discussão realizada apresentou exemplos de duas abordagens básicas sobre os determinantes da política de proteção - chamadas aqui de modelos da economia política histórica e da economia política positiva. Os autores do primeiro grupo distinguem-se pelo uso da análise histórica para a identificação de comportamentos regulares de atores sociais e a elaboração de hipóteses sobre os fatores causais que determinam o protecionismo. As abordagens da economia política histórica possuem em comum a premissa de que os regimes comerciais adotados por países são produto da interação de interesses econômicos, valores e instituições em contextos históricos específicos, antes do que o resultado puro da operação das forças de mercado. Na síntese apresentada acima, foram destacados autores que privilegiam o papel de grupos de interesse na explicação das variações e níveis da proteção em um determinado país. No entanto, como foi sustentado antes, há outros aspectos que são destacados como condicionantes da política comercial - Estado, idéias e o sistema internacional. De fato, alguns autores têm argumentado convincentemente que a ação de grupos de interesse no âmbito da formulação de políticas econômicas externas é altamente dependente das estruturas políticas existentes, das organizações do Estado e da inserção particular de uma economia no sistema econômico e político internacional. ${ }^{6}$

Já os modelos da economia política positiva partem das teorias da escolha racional e da ação coletiva a fim de estabelecer hipóteses testáveis empiricamente quanto às influências de grupos de interesse, situações políticas e condições econômicas que podem determinar a proteção comercial. Esses modelos procuram mostrar como a atuação de grupos movidos por interesses particularistas pode condicionar a formulação de políticas protecionistas, dependendo de seu peso econômico e político, das condições eleitorais, da posição competitiva da indústria e da possibilidade de retaliações por parte de parceiros comerciais. Apesar de seu alto grau de abstração, esses modelos têm sido crescentemente utilizados em estudos sobre as causas do protecionismo.

Ambas as abordagens têm obtido importantes resultados empíricos, que podem ser úteis na compreensão das condições presentes no ambiente econômico e social que tendem a dar origem a políticas protecionistas. Estudos inspirados nos modelos da economia política positiva apontam, por exemplo, que o sucesso na obtenção de benefícios protecionistas tem ocorrido em casos em que a indústria utiliza intensivamente mão-de-obra, baixos salários e baixa mobilidade de capital; quando o mercado sofre alta taxa de penetração de importações; a produção é regionalmente concentrada ou existem poucos produtores; e o produto é de consu-

\footnotetext{
${ }^{6}$ Ver particularmente Simmons (1994) e Gourevitch (1977), p. 122-5.
} 
mo final, o que requer também que os consumidores não sejam concentrados (Rodrik, 1995, p. 1481).

Por sua vez, modelos da economia política histórica têm mostrado, por exemplo, que as condições políticas e econômicas domésticas são importantes para o tipo de ajuste adotado diante de condições adversas nas contas externas. Decisões de internalizar ou externalizar os custos do ajuste através de desvalorização e/ou proteção tendem a ser condicionadas pela política doméstica. Governos fracos e instáveis, por exemplo, são propensos a rejeitar ajustes com impactos negativos sobre as rendas de grupos sociais influentes e que podem reduzir ainda mais a sua base de sustentação política. Assim, a fragilidade política de uma coalizão governamental tende a estar correlacionada com maior protecionismo em situações de desequilíbrio externo. Por outro lado, crises econômicas, com queda da produção industrial e desemprego, tendem a produzir reações por parte dos grupos afetados em favor de medidas protecionistas (Simmons, 1994, p. 186-98).

Ao mesmo tempo em que produzem resultados relevantes que podem ser utilizados como ponto de partida para análises empíricas e históricas, os modelos discutidos acima também apresentam dificuldades e limitações. Por exemplo, um dos maiores problemas de que se ressentem os modelos de economia política histórica é a reduzida clareza com relação, primeiro, às variáveis consideradas centrais na determinação das políticas comerciais e, segundo, às hipóteses de comportamento dos agentes envolvidos na formulação dessas políticas. No primeiro caso, a análise de Gerschenkron é ilustrativa. Embora o autor enfatize o papel dos grupos de interesse, a influência efetiva desses últimos foi vista como condicionada por fatores tão variados como a história de organização dos junkers, as organizações políticas alemãs, a habilidade e interesses políticos de Bismarck, a cultura autoritária predominante e a situação econômica internacional. Se por um lado essa multiplicidade de elementos determinantes enriquece historicamente a análise de Gerschenkron, por outro lado perde-se em nitidez quanto aos fatores que poderiam ser generalizados como parte de uma teoria da economia política da proteção comercial. Quanto às hipóteses de comportamento dos agentes, o estudo de Gerschenkron também é ilustrativo. O autor implicitamente assume que os interesses de grupos sociais são determinados genericamente em função da sua posição nas relações de propriedade e poder em que estão envolvidos, mediadas por tradições, ideologias e instituições estabelecidas em cada contexto regional e histórico. A dificuldade é que o nível de generalidade dessa hipótese comportamental exclui do horizonte da análise problemas da ação coletiva que afetam a formação, a organização e a efetividade de grupos de interesse. A ausência de uma abordagem micro das escolhas, ações e estratégias pode deixar em aberto questões centrais sobre por que e como os atores sociais adotaram determinada linha de ação, cuja lógica muitas vezes não pode ser explicada somente pelo recurso a condicionantes econômicos, sociais e políticos gerais. 
Com relação aos modelos da economia política positiva, os problemas são deoutra natureza e, em certo sentido, opostos aos da economia política histórica. Isso pode ser visto quando os modelos da economia política positiva assumem que o comportamento dos agentes (empresas, políticos, governos) é diretamente derivado das propriedades abstratas da escolha racional e de medidas quantitativas, relacionadas por exemplo ao número de trabalhadores da indústria, tamanho do mercado e contribuições financeiras. Embora sejam aproximações úteis que auxiliam na explicação do comportamento dos agentes que influenciam a proteção comercial, as propriedades gerais da escolha racional e as medidas quantitativas baseiam-se, em primeiro lugar, em simplificações dos motivos que orientam a ação dos atores econômicos em seus contextos institucionais e históricos. Em segundo lugar, e talvez mais importante, o uso de medidas quantitativas para explicar o comportamento dos agentes tende a gerar resultados empíricos ambíguos e altamente dependentes das hipóteses adotadas (Potters \& Sloof, 1996). Nesse sentido, uma análise mais sensível às tentativas de teorização e à reconstituição histórica das instituições (entendidas como regras do jogo, formais e informais) e dos grupos sociais associados às políticas de proteção comercial pode ser considerada um passo essencial na investigação das causas do protecionismo. Aqui, a crítica de North (1981, cap. 5) à insuficiência e inadequação de uma teoria que pressupõe atores econômicos definindo sua ação através do cálculo estrito de custo/benefício pode também ser considerada relevante.

Independentemente de seus problemas e limitações, porém, e retornando ao ponto inicial dessa resenha, as abordagens e modelos comentados aqui apresentam o reconhecimento teórico de que o protecionismo é um fenômeno mais complexo e persistente do que talvez tenha sido comum admitir em décadas anteriores. De fato, antes do domínio universal do livre-comércio - como chegou a ser proposto nos anos que seguiram à II Guerra Mundial —, o que se tem visto nas últimas décadas é a criação de novas formas protecionistas, ao lado das antigas, que reproduzem interesses econômicos, instituições e condições sócio-políticas variáveis das nações, que se refletem na economia internacional. Se isso for verdadeiro, é provável que o protecionismo continuará sendo um objeto central da análise econômica, que desafia abordagens simplificadoras e requer uma perspectiva eminentemente interdisciplinar.

\section{REFERÊNCIAS BIBLIOGRÁFICAS}

ARAÚJO Jr., J. (1995) “Economía política del proteccionismo después de la Ronda Uruguay”. Revista de la Cepal. 55, Abril: 55-64.

BALDWIN, R. (1995) “The New Protectionism: a response to shifts in national economic power". In: FRIEDEN, J.; LAKE, D., eds (1995).

EICHENGREEN, B. (1989) "The political economy of the Smooth-Hawley Tariff”. In: FRIEDEN, J.; LAKE, D., eds. (1995). 
FINGER, M.; HALL, K. and NELSON, D. (1982) "The political economy of administered protection". American Economic Review. 72 (3), June: 452-66.

FRIEDEN, J.; LAKE, D., eds. (1995), International political economy. Perspectives on global power and wealth. 3rd ed. London: Routledge.

GERSCHENKRON, A. (1943) Bread and democracy in Germany. Ithaca: Cornell University Press, 1989. GOLDSTEIN, J. (1988) "Ideas, institutions, and American trade policy". In: FRIEDEN, J.; LAKE, D., eds. (1995).

GOUREVITCH, P. (1977) "International trade, domestic coalitions, and liberty: comparative responses to the crisis of 1873-1896". In: ROGOWSKI, R. ed. (1995).

GROSSMAN, G.;HELPMAN, E. (1994) “Protection for sale”. American Economic Review, 84 (4), September: 833-50.

GROSSMAN, G.; ROGOFF, K., eds. (1995), Handbook of international economics. Amsterdam: Elsevier Science, 1995, vol. III.

HILLMAN, A. (1982) "Declining industries and political-support protectionist motives". American Economic Review. 72 (5), December: 1180-87.

HILLMAN, A.; URSPRUNG, H. (1988) "Domestic politics, foreign interests, and international trade policy”. American Economic Review. 78 (4), September: 729-45.

KINDLEBERGER, C. (1951) "Group behavior and international trade". In: ROGOWSKI, R., ed. (1995). KRASNER, S. (1976) "State power and the structure of international trade". In: FRIEDEN, J.; LAKE, D., eds. (1995).

LENWAY, S.; MORCK, R. and YOUNG, B. (1996) "Rent seeking, protectionism, and innovation in the American steel industry". Economic Journal. 106 (435), March: 410-421.

MAIER, C. (1987) "Introduction: political economy and history". In: MAIER, C. (1987)

MAIER, C. (1987) In search of stability. Explorations in historical political economy. Cambridge: Cambridge University Press.

NORTH, D. (1981) Structure and change in economic history. New York, W.W. North.

OLSON, M. (1965) The logic of collective action. Public goods and the theory of groups. Cambridge, Mass.: Harvard University Press.

ORDERSHOOK, P. (1990) “The emerging discipline of political economy”. In: ALT, J.; SHEPSLE, K.

Perspectives on positive political economy. Cambridge: Cambridge University Press, 1990. POTTERS, J.; SLOOF, S. (1996) "Interest groups: a survey of empirical models that try to assess their influence”. European Journal of Political Economy. 12: 403-42, 1996.

RODRIK, D. (1995) "Political economy of trade policy". In: GROSSMAN, G.; ROGOFF, K., eds. (1995). ROGOWSKI, R. (1989) Commerce and coalitions: how trade affects domestic political alignments. Princeton: Princeton University Press.

ROGOWSKI, R., ed. (1995) Comparative politics and the international political economy. Aldershot: Edward Elgar.

ROSENDORF, P. (1996) "Voluntary export restraints, antidumping procedure, and domestic politics". American Economic Review. 86 (3), June: 544-561.

SIMMONS, B. (1994) Who adjusts? Domestic sources of foreign economic policy during the interwar years. Princeton: Princeton University Press.

WINTERS, A. (1991) International economics. 4th ed. London: Routledge. 